\title{
Progression of subclinical polyneuropathy in young patients with Type 1 (insulin-dependent) diabetes: associations with glycaemic control and microangiopathy (microvascular complications)
}

\author{
R.J. Young ${ }^{1}$, C.C.A. Macintyre4, C. N. Martyn ${ }^{3}$, R. J.Prescott ${ }^{4}$, D.J.Ewing ${ }^{3}$, A. F. Smith ${ }^{2}$, \\ G. Viberti ${ }^{5}$ and B. F. Clarke ${ }^{1,3}$ \\ ${ }^{1}$ Diabetic and Dietetic Department, ${ }^{2}$ Clinical Chemistry Department and ${ }^{3}$ University Department of Medicine, Royal Infirmary, \\ ${ }^{4}$ Medical Computing and Statistics Unit, Edinburgh University, Edinburgh and ${ }^{5}$ Unit for Metabolic Medicine, \\ Guy's Hospital Medical School, London, UK
}

Summary. The progression of subclinical polyneuropathy over 2.5 years has been studied in a representative group of 75 young patients with Type 1 (insulin-dependent) diabetes (initial age 16-19 years). The relationships between changes in nerve function, glycaemic control and concurrently developing microvascular complications (retinopathy, microproteinuria) were investigated. Deterioration of motor, sensory and autonomic nerve function, retinopathy and microproteinuria was related to poor glycaemic control. In addition, there was an association between developing neural and microvascular complications which was not diminished when their common relationship to hyperglycaemia was taken into account. These findings suggest that, although poor glycaemic control is an essential permissive factor in the early development of diabetic polyneuropathy, other influences, shared with microvascular complications, must also be important.

Key words: Diabetic neuropathy, glycaemic control, microvascular complications.
A diffuse polyneuropathy involving somatic and autonomic nerve fibres is a frequent complication of diabetes $[1,2]$. It causes considerable morbidity [3] and is associated with increased mortality [4]. The primary role of hyperglycaemia in the development and progression of diabetic complications is still unclear. Although there is substantial evidence for a metabolic component in the pathogenesis of neuropathy [5], diabetic neural microangiopathy may also be a causal factor [6]. Many other aetiopathogenic mechanisms have been suggested $[6,7]$.

We have reported previously that abnormalities of motor, sensory and autonomic nerve function were common in 81 teenage patients with Type 1 (insulin-dependent) diabetes asymptomatic of neuropathy [8]. The presence and severity of electrophysiological but not autonomic abnormalities were related to poor glycaemic control [8]. This same group of patients has now been followed up for an average of 2.5 years in order to determine whether progression of early diabetic neuropathy is related to glycaemic control or early microvascular complications.

\section{Subjects and Methods}

\section{Subjects}

Seventy-five of the original cohort of 81 young patients with Type 1 (insulin-dependent) diabetes were followed for approximately 2.5 years and then reassessed (mean follow-up 28 months, range $20-35$ months). Initially their age was $16-19$ years and duration of diabetes ranged from 6 months - 17 years (median 5 years). Of the other six, one did not wish to be reassessed, three had moved away from Edinburgh, and two had died (one of cardiomyopathy unrelated to diabetes, the other of prolonged hypoglycaemia). All patients received standard diabetic care, and no other attempt was made to influence glycaemic control.

At reassessment, symptoms of peripheral and autonomic neuropathy were elicited and a scored clinical examination of the peripheral nerves carried out as described previously [9]. Three had symptoms of neuropathy at reassessment. One female developed acute painful neuropathy with onset just at review and one male noted numbness and tingling in the toes; both had abnormalities on clinical sensory testing. Another female complained of abnormal sweating. Ankle reflexes were absent in seven ( 3 males, 4 females), including the male who had numbness, but clinical testing of sensory function was otherwise within normal limits.

Control measurements were obtained in 49 healthy non-diabetic subjects (25M:29F) aged 16-22 years (schoolboys, student nurses and medical students). Twenty (age 16-19 years) were tested initially and 29 (age 18-22) at review. Since there was no significant difference between the results for the initial and review control groups, all the values were pooled for further analysis.

Participation in the study by both patients and control subjects was approved by the Hospital Advisory Ethical Committee.

\section{Biochemistry}

Total glycosylated haemoglobin $\left(\mathrm{HbA}_{1}\right)$ was measured by an electrophoretic method [10] at entry to the study and thereafter at every routine clinic visit (normal range 6-8\%). The second $\mathrm{HbA}_{1}$ value used in the analysis represents the mean of all subsequent measurements (i.e. the mean $\mathrm{HbA}_{1}$ during followup). No patient was hypoglycaemic or ketonuric initially or at reassessment and plasma thyroxine was normal in all.

\section{Peripheral nerve electrophysiology}

Motor and sensory nerve conduction studies were performed in the left arm and leg using a DISA (Bristol, UK) 1500 electromyograph with surface electrodes, thermostatically regulated skin temperature 
Table 1. Nerve function measurements used in prospective analysis [mean $\pm \mathrm{SD}$ (range)] for control subjects and diabetic patients.

\begin{tabular}{|c|c|c|c|c|c|c|c|c|}
\hline \multirow[t]{2}{*}{ Test } & \multirow{2}{*}{$\begin{array}{l}\text { Non-diabetic } \\
\text { control } \\
\text { subjects }\end{array}$} & \multirow{2}{*}{$\begin{array}{l}\text { Diabetic patient } \\
\text { first measurement } \\
\text { DM1 }\end{array}$} & \multirow{2}{*}{$\begin{array}{l}\text { Diabetic patient } \\
\text { second measurement } \\
\text { DM2 }\end{array}$} & \multicolumn{3}{|c|}{$\begin{array}{l}\text { Significance of } \\
\text { differences }\end{array}$} & \multicolumn{2}{|c|}{$\%$ Abnormal values } \\
\hline & & & & $\begin{array}{l}\text { DM1 } \\
\text { vs } \\
\text { Control }\end{array}$ & $\begin{array}{l}\text { DM2 } \\
\text { vs } \\
\text { Control }\end{array}$ & $\begin{array}{l}\text { DM1 } \\
\text { vs } \\
\text { DM2 }\end{array}$ & DM1 & DM2 \\
\hline $\begin{array}{l}\text { Peroneal MNCV } \\
\left(\mathrm{ms}^{-1}\right)\end{array}$ & $\begin{array}{c}51.1 \pm 3.1 \\
(44.2-58.7)\end{array}$ & $\begin{array}{c}43.7 \pm 4.6 \\
(30.9-52.3)\end{array}$ & $\begin{array}{c}42.4 \pm 5.0 \\
(26.4-51.8)\end{array}$ & $* * *$ & $* * *$ & $* *$ & 63 & 66 \\
\hline $\begin{array}{l}\text { Sural SNCV } \\
\left(\mathrm{ms}^{-1}\right)\end{array}$ & $\begin{array}{c}37.0 \pm 3.7 \\
(28.8-45.0)\end{array}$ & $\begin{array}{c}34.6 \pm 6.0 \\
(16.7-44.4)\end{array}$ & $\begin{array}{c}32.2 \pm 5.7 \\
(12.0-41.7)\end{array}$ & $*$ & $* * *$ & $* *$ & 19 & 24 \\
\hline $\begin{array}{l}\text { Sural SPA } \\
(\mu V)\end{array}$ & $\begin{array}{l}11.0 \pm 5.1 \\
(4-28)\end{array}$ & $\begin{array}{l}11.1 \pm 7.8 \\
(0.5-40)\end{array}$ & $\begin{array}{l}8.1 \pm 6.0 \\
(0-24)\end{array}$ & NS & * & $* *$ & 20 & 29 \\
\hline $\begin{array}{l}\text { Max-min HR } \\
\text { (beats/min) }\end{array}$ & $\begin{array}{l}34.2 \pm 8.1 \\
(16-53)\end{array}$ & $\begin{array}{l}28.6 \pm 10.7 \\
(6-55)\end{array}$ & $\begin{array}{l}29.4 \pm 13 \\
(5-64)\end{array}$ & $*$ & $*$ & NS & 19 & 28 \\
\hline
\end{tabular}

Significances of group differences $(*=p<0.05, * *=p<0.01, * * *=p<0.001)$.

Percent abnormal values (abnormal $=<$ second lowest value for control subjects)

control $\left(32^{\circ} \mathrm{C}\right)$, supramaximal stimuli and averaging of compound sensory action potentials as previously described [8]. Motor nerve conduction velocities (MNCV) and amplitudes of evoked muscle action potentials were recorded in the median and peroneal nerves. Sensory nerve conduction velocity (SNCV) and sensory action potential amplitudes (SPA) were measured in the median and sural nerves. Motor and sensory electrophysiological measurements were highly correlated as before [8]. To clarify presentation, therefore, the three measurements in the leg (peroneal MNCV, sural SNCV, sural SPA) were combined into a single expression (the arm measurements were not used in analysis - see Results). Each individual measurement was standardised by subtracting it from the mean and dividing by the standard deviation for control subjects. The three standardised variables for each subject could then be summed to give a single combined electrophysiological variable for the leg (CEVL).

\section{Cardiovascular autonomic function tests}

Five cardiovascular autonomic function tests were performed as previously described [11]. Three used heart rate responses to: the Valsalva manoeuvre (Valsalva ratio), standing up (30:15 ratio), and deep breathing (max-min heart rate). Two tests record blood pressure responses; one to standing up (post BP) and the other to sustained handgrip (grip).

\section{Retinopathy}

The retinae were examined in a darkened cubicle through adequately dilated pupils using a direct ophthalmoscope. Visible retinopathy was graded as $0=$ no retinopathy, $1=$ microaneurysms only, $2=$ haemorrhages/venous change, $3=$ hard exudates/cotton wool spots/intraretinal microvascular abnormalities, and $4=$ new vessels.

\section{Microproteinuria}

At reassessment urinary albumin concentration (UAC) was measured in a single untimed overnight urine sample by a sensitive radio-immunoassay method [12] in all but 4 patients.

\section{Blood pressure}

The values used were the average of three systolic and diastolic blood pressure measurements taken using a mercury sphygmomanometer with the subject sitting at rest in a firm armchair.

\section{Statistical analysis}

Data was analysed by the BMDP statistical software package (University of California, 1983). Standard parametric (Student's t-tests, ANOVA) and non-parametric (Mann-Whitney) tests were applied to group comparisons. Univariate linear or logistic regression analysis
Table 2. Retinopathy at review related to duration of diabetes

\begin{tabular}{lrrrrrc}
\hline $\begin{array}{l}\text { Grade } \\
\text { retinopathy } \\
\text { at review }\end{array}$ & \multicolumn{6}{c}{ Duration of diabetes at review (years) } \\
\cline { 2 - 7 } & $2-4$ & $5-6$ & $7-9$ & $10-14$ & $15+$ & Total \\
\hline 0 & 11 & 14 & 16 & 6 & 3 & 50 \\
1 & 0 & 0 & 3 & 3 & 3 & 9 \\
2 & 0 & 0 & 4 & 1 & 2 & 7 \\
3 & 0 & 0 & 1 & 2 & 3 & 6 \\
4 & 0 & 0 & 2 & 1 & 0 & 3 \\
Total & 11 & 14 & 26 & 13 & 11 & 75 \\
\hline
\end{tabular}

a Grade of retinopathy: $0=$ none; $1=$ microaneurysms; $2=$ haemorrhages; $3=$ exudates $/$ IRMA; $4=$ new vessels

was used to study the associations between characteristics. To examine which of the significant univariate associations persisted when previous measurements of the dependent variable and glycaemia were considered, multiple regression analysis was then performed. Allowance for the effect of the initial measurement on the reassessment measurement in the dependent variable is equivalent to testing for associations with changes (improvement or deterioration) between the initial and review measurement in that variable. Taking glycaemia $\left(\mathrm{HbA}_{1}\right)$ into account determines whether the associations between developing complications are independent or merely due to a common association with glycaemia.

\section{Results}

\section{Abnormalities in diabetic patients}

Nerve function. The electrophysiological results for peroneal MNCV, sural SNCV and sural SPA and the cardiovascular autonomic reflex measurement max-min HR are given in Table 1 . The remaining electrophysiological and cardiovascular reflex measurements either showed no difference from control subjects (Valsalva ratio, grip), no change between initial and reassessment measurements (median MNCV, median SNCV) or insufficient reproducibility for analysis (median SPA, $30: 15$ ratio). The electrophysiological results in the leg have been combined to form the term CEVL (see Methods) for further analysis. At reassessment more patients had developed abnormal peripheral nerve electrophysiology in the leg (32\% abnormal initially, $41 \%$ ab- 
normal at review) and abnormal max-min HR (19\% abnormal initially, $28 \%$ abnormal at review) because deterioration occurred twice as often as improvement.

Retinopathy, urinary albumin concentration, blood pressure. Initially five patients $(7 \%)$ with diabetes of more than 10 years duration had grade 1 retinopathy. At reassessment the number with detectable retinopathy had risen to $25(33 \%)$, nine $(12 \%)$ having grade 3 or 4 retinopathy (Table 2). Retinopathy was not detected in anyone with diabetes of duration less than 7 years.

Urinary albumin concentration was above the range for normal subjects $(1 \mathrm{mg} / 100 \mathrm{ml})$ in $28 / 71(40 \%)$ of diabetic patients. No patient had Albustix positive proteinuria initially, although one patient did at reassessment $(\mathrm{UAC}=508 \mathrm{mg} / 100 \mathrm{ml})$.

Mean systolic blood pressure did not differ between diabetic patients and control subjects but was higher in males than females (M 125 \pm 2 SEM vs F $114 \pm 2$ SEM
$\mathrm{mmHg}$ ). Mean diastolic blood pressure was not significantly different in the diabetic group than in control subjects (diabetic patients $78 \pm 1.5 \mathrm{SEM}$, control subjects $74 \pm 1.5 \mathrm{SEM} \mathrm{mmHg}$ ). Ten diabetic patients initially $(12 \%)$ and 15 at review $(20 \%)$ had diastolic blood pressures above the highest value for control subjects (range for diabetic group 56-102, control group $56-86 \mathrm{mmHg}$ ).

\section{Analysis of associations between abnormalities}

Investigation of possible associations. Each of the review observations, CEVL (combined electrophysiology variable leg), max-min HR, retinopathy, diastolic blood pressure (DBP), urinary albumin concentration (UAC) were entered as a dependent variable in the regression analysis. The possible influence of each of the following factors was considered: age, sex, body mass index, duration of diabetes, previous episodes of ketoacidosis, frequency of symptomatic hypoglycaemia, smoking

Table 3. Results of regression analyses. The relationship of all the characteristics mentioned in the text to each of the five dependent variables has been examined. Only the results of significant $(*=p<0.05, * *=p<0.01, * * *=p<0.001)$ associations are shown

\begin{tabular}{|c|c|c|c|}
\hline Dependent variable & $\begin{array}{l}\text { Significantly associated } \\
\text { independent variables }\end{array}$ & $\begin{array}{l}\text { Correlation } \\
\text { coefficient } \mathrm{c}\end{array}$ & $\begin{array}{l}\text { Partial correlation coefficient after accounting } \\
\text { for initial values and } \mathrm{HbA}_{1}(\mathrm{mn}) \mathrm{d}\end{array}$ \\
\hline $\begin{array}{l}\text { Electrophysiology } \\
{\text { Leg }(r)^{\mathrm{a}}}\end{array}$ & $\begin{array}{l}\text { Electrophysiology leg (i) } \\
\mathrm{HbA}_{1}(\mathrm{mn}) \\
\text { Duration DM } \\
\mathrm{HbA}_{1}(\mathrm{i}) \\
\text { Retinopathy (i) } \\
\text { Retinopathy (r) } \\
\text { Diastolic BP (r) } \\
\text { Max-min HR (r) } \\
\text { Urinary albumin concentration }\end{array}$ & $\begin{array}{l}0.55^{* * *} \\
-0.59^{* * *} \\
-0.24^{*} \\
-0.32^{* *} \\
-0.29^{*} \\
-0.68^{* * *} \\
0.30^{*} \\
0.30^{*} \\
-0.47^{* * *}\end{array}$ & $\begin{array}{l}- \\
- \\
\text { NS } \\
- \\
-0.35^{* * *} \\
-0.53^{* * *} \\
\text { NS } \\
\text { NS } \\
-0.47^{* * *}\end{array}$ \\
\hline $\begin{array}{l}\text { Max-min } \\
\quad \text { heart rate }(r)^{a}\end{array}$ & $\begin{array}{l}\text { Max-min HR (i) } \\
\mathrm{HbA}_{1}(\mathrm{mn}) \\
\text { Retinopathy (r) } \\
\text { Electrophysiology leg (r) } \\
\text { Urinary albumin concentration }\end{array}$ & $\begin{array}{c}0.54^{* * *} \\
-0.27^{*} \\
-0.30^{*} \\
0.30^{*} \\
-0.35^{* *}\end{array}$ & $\begin{array}{l}- \\
- \\
\text { NS } \\
\text { NS } \\
-0.34^{* *}\end{array}$ \\
\hline $\begin{array}{l}\text { Urinary } \\
\text { albumin concentration }(\mathrm{r})^{\mathrm{a}}\end{array}$ & $\begin{array}{l}\mathrm{HbA}_{1}(\mathrm{mn}) \\
\text { Retinopathy (r) } \\
\text { Diastolic BP (r) } \\
\text { Electrophysiology leg (r) } \\
\text { Max-min HR (r) }\end{array}$ & $\begin{array}{l}0.29 * \\
0.41 * * * \\
0.41 * * * \\
-0.47^{* * *} \\
-0.35 * *\end{array}$ & $\begin{array}{r}0.32 * \\
0.36 * * \\
-0.39 * * \\
-0.29 *\end{array}$ \\
\hline $\begin{array}{l}\text { Diastolic } \\
\quad \text { blood pressure }(r)^{\mathrm{a}}\end{array}$ & $\begin{array}{l}\text { Diastolic BP (i) } \\
\mathrm{HbA}_{1}(\mathrm{mn}) \\
\text { Sex } \\
\text { Retinopathy (r) } \\
\text { Electrophysiology leg (r) } \\
\text { Urinary albumin concentration }\end{array}$ & $\begin{array}{l}0.49^{* * *} \\
0.25^{*} \\
-0.27^{*} \\
0.34^{* *} \\
-0.30^{*} \\
0.41^{* * *}\end{array}$ & $\begin{array}{l}- \\
- \\
-0.28^{*} \\
0.28^{*} \\
\mathrm{NS} \\
0.40^{* * *}\end{array}$ \\
\hline & & t-statistic c & $\begin{array}{l}\text { Significance after allowing for duration DM } \\
\text { initial values and } \mathrm{HbA}_{1} \mathrm{~d}\end{array}$ \\
\hline Retinopathy $(r)^{b}$ & $\begin{array}{l}\text { Duration DM } \\
\mathrm{HbA}_{1}(\mathrm{i}) \\
\mathrm{HbA}_{1}(\mathrm{mn}) \\
\text { Diastolic BP (r) } \\
\text { Urinary albumin concentration } \\
\text { Electrophysiology leg (i) } \\
\text { Electrophysiology leg (r) } \\
\text { Max-min HR (r) }\end{array}$ & $\begin{array}{l}-3.08^{* *} \\
-4.61^{* * *} \\
-4.81^{* * *} \\
-3.02^{* *} \\
-3.11^{* *} \\
4.06^{* * *} \\
4.91 * * * \\
2.98 * *\end{array}$ & $\begin{array}{l}- \\
- \\
- \\
* * \\
* \\
\text { NS } \\
* \\
*\end{array}$ \\
\hline
\end{tabular}

[(i)=initial; $(\mathrm{r})=$ review; $(\mathrm{mn})=$ average during followup]

${ }^{a}$ Linear regression analysis; ${ }^{b}$ logistic regression analysis in which retinopathy (r) was classified as grade $0=$ no, grade $1-4=$ yes; ${ }^{c}$ univariate associations between dependent and independent variables; ${ }^{d}$ associations which persisted in multivariate analysis after allowing for $\mathrm{Hb}_{1}$ and initial values 

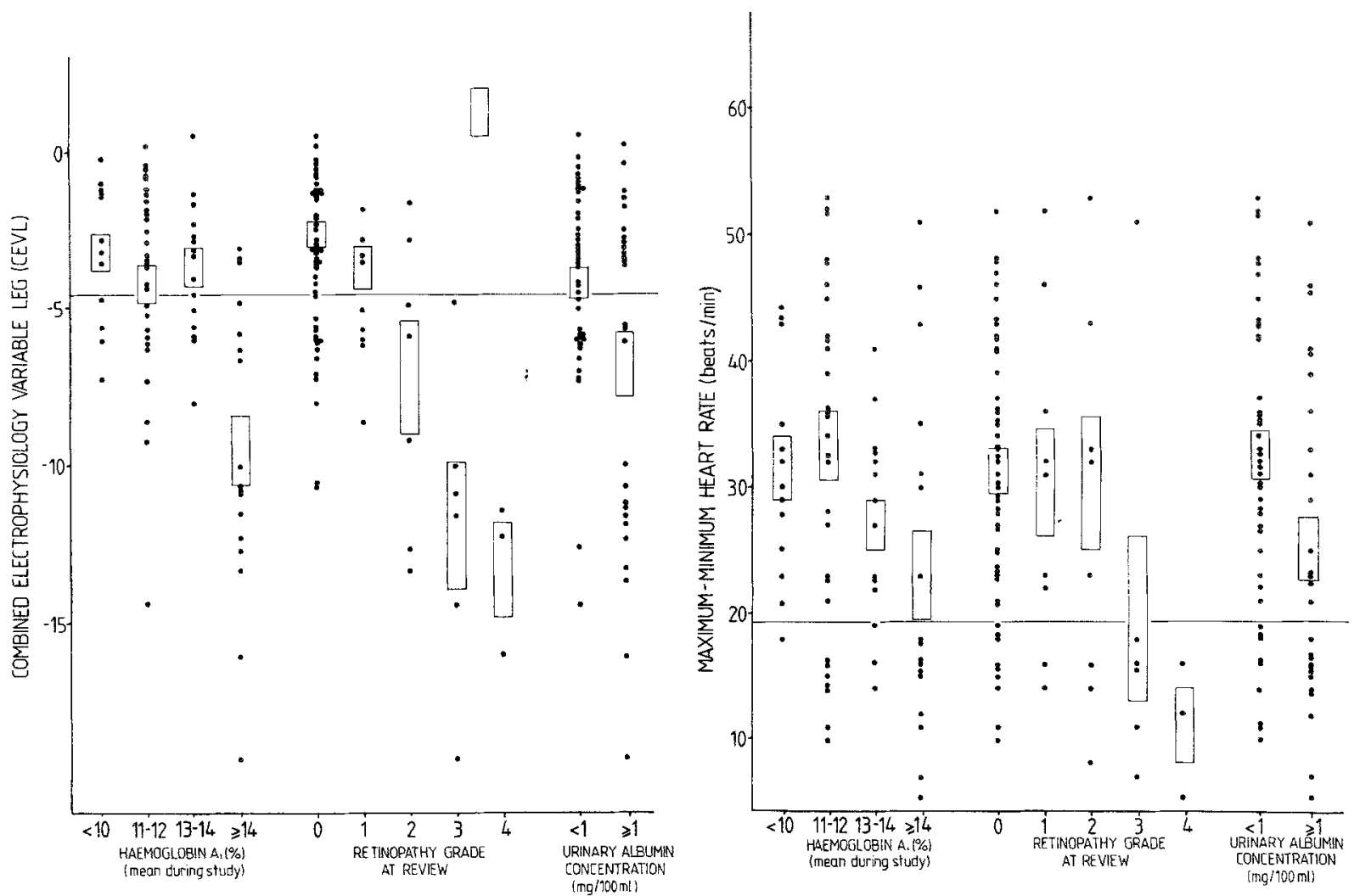

Fig. 1. The relationships of peripheral somatic (combined electrophysiology variable leg) and autonomic nerve (max-min heart rate) function to glycosylated haemoglobin (mean over 2.5 years), grade of retinopathy and urinary albumin concentration in 75 young patients with Type 1 (insulin-dependent) diabetes. Bars represent mean \pm SEM. Values above the continuous horizontal lines are within the range for non-diabetic control subjects

habit, alcohol consumption, and both original and review values of $\mathrm{HbA}_{1}, \mathrm{CEVL}$, max-min $\mathrm{HR}, \mathrm{DBP}$ and $\mathrm{UAC}$ (at reassessment only). Using multiple regression, the associations that remained when the initial values (investigating change in the dependent variable) and $\mathrm{HbA}_{1}$ levels (testing for independence of associations from hyperglycaemia) had been taken into account were then determined.

Associations with nerve function abnormalities. The factors significantly related to CEVL and max-min HR are shown in Table 3 . As reported for initial measurements in the original cross-sectional study [8] both duration of diabetes and $\mathrm{HbA}_{1}$ were associated with electrophysiological abnormalities. In this study there was also a significant, although weak, cross-sectional relationship between hyperglycaemia and abnormal autonomic function (max-min HR) at review which had not reached statistical significance initially. When the effect of the initial measurement on the review measurement was taken into account, this prospective study showed that $\mathrm{HbA}_{1}$ was correlated with deterioration in CEVL (partial correlation coefficient $=-0.59, p<0.001$ ) and deterioration in max-min HR (partial correlation coefficient $=-0.27, p<0.05$ ).

Abnormalities in CEVL and max-min HR were both associated with the presence and grade of retinopathy and with urinary albumin concentration when the review measurement or deterioration during followup was considered (Table 3 ). With the exception of the relationship between max-min HR and retinopathy, the associations between nerve and microvascular abnormalities were independent of glycaemia.

Figure 1 illustrates these relationships between CEVL or max-min HR and $\mathrm{HbA}_{1}$, retinopathy and urinary albumin concentration. Although the electrophysiological findings in the leg have been expressed as a single variable, CEVL in this analysis, the individual measurements (peroneal MNCV, sural SNCV, sural SPA) each gave similar conclusions if considered separately.

\section{Associations with retinopathy, raised urinary albumin concentration, raised diastolic $B P$}

The significant relationships for these dependent variables are also shown in Table 3 . The presence or grade of retinopathy was positively correlated with duration of diabetes, $\mathrm{HbA}_{1}$, urinary albumin concentration, diastolic blood pressure and abnormal CEVL or max-min HR. The development of retinopathy was predicted both by high initial $\mathrm{HbA}_{1}$ or abnormal initial electrophysiology. Urinary albumin concentration was weakly associated with $\mathrm{HbA}_{1}$ but more closely with retinopathy, abnormal nerve function and diastolic blood pressure. Diastolic blood pressure at review was related to urinary albumin concentration and retinopathy and was higher in male diabetic patients. 
Comparison of relationships with deteriorating nerve function: glycaemia vs microvascular complications

Some diabetic patients with very poor glycaemic control throughout the study $\left(\mathrm{HbA}_{1}>14 \%\right)$ had electrophysiological and autonomic measurements which remained within the normal range (Fig. 1). In contrast, all but one of the electrophysiological and autonomic measurements were abnormal in patients with grade 3 or 4 retinopathy (Fig. 1). The relationship between abnormal UAC and CEVL was not so clear cut, but $11 / 13(85 \%)$ of those with very low CEVL $(<-10)$ had abnormal UAC (Fig. 1), and the association between max-min HR and UAC was closer than that of either with $\mathrm{HbA}_{1}$.

\section{Discussion}

These results show that in young patients with Type 1 (insulin-dependent) diabetes, motor and sensory peripheral somatic nerve function and autonomic nerve function deteriorate at a rate which is linearly related to the prevailing level of glycaemia. The development of retinopathy and raised urinary albumin concentration were also related to poor glycaemic control. In addition, there was an association between deteriorating nerve function and the concomitant development of microvascular complications (retinopathy and microproteinuria) which was statistically independent of their common association with glycaemia.

In this study a relationship between degree of hyperglycaemia and changes in sensory and autonomic nerve function has been demonstrated. The recently reported small deterioration in vibration perception associated with poor glycaemic control $[13,14]$ is the only relationship between hyperglycaemia and sensory neuropathy hitherto identified. There have been no comparable studies of autonomic function. The concept of direct metabolic damage to nerves by hyperglycaemia [5] is based on studies of motor nerve conduction velocity [15-22]. Yet it is sensory and autonomic nerve involvement, rather than damage to somatic motor fibres, which is responsible for the common and clinically serious manifestations of diabetic neuropathy $[3,6]$. In patients symptomatic of symmetrical sensory diabetic polyneuropathy, the degree of abnormality in neurophysiological tests such as those performed in this study is clearly related to the presence and clinical manifestation of the neuropathy [23]. No sequential study has yet established that subclinical abnormalities of nerve function, even in sensory and autonomic nerves, are predictive of subsequent clinical neuropathy. Nevertheless, it seems likely that the sustained and progressive changes in sensory and autonomic nerve function demonstrated in this study do reflect nerve damage that is likely to become of clinical importance, particularly since, unlike motor nerves, rapid improvements in the function of these nerves have not been observed in response to improved metabolic control.

Poor glycaemic control was also associated with both the onset and severity of retinopathy. The high rate of appearance of retinopathy in late teenage diabetes has been noted before [24]. The role of hyperglycaemia in the development and progression of microangiopathy is controversial [25]. Previous prospective studies, which relied on less satisfactory indices of glycaemic control than $\mathrm{HbA}_{1}[1,26,27]$, have suggested a link between the onset of retinopathy and poor control, whereas improving glycaemic control in established retinopathy has shown no convincing modification of progression [21, 28-30]. In our study the development of retinopathy was accompanied by a rise in diastolic blood pressure, especially in males, but multiple regression analysis showed that raised diastolic blood pressure was more closely associated with raised urinary albumin concentration than with retinopathy. Raised but subclinical it proteinuria is probably, at least in part, functional. Like motor nerve conduction velocity, it improves with near-physiological glycaemic control [12], although higher levels are related to subsequent clinical nephropathy [31-33]. Weak relationships between poor glycaemic control, raised urinary albumin concentration and raised blood pressure, as shown in this study, have been reported previously [34].

Peripheral somatic and autonomic neuropathy, retinopathy and microproteinuria were, individually related to the level of hyperglycaemia. Perhaps not surprisingly, therefore, there were also associations between the developing neural and microvascular abnormalities. But multivariate analysis showed that these neural/microvascular associations remained just as strong after their common relationship to poor glycaemic control was taken into account. This does not imply that either type of complication could develop in the absence of hyperglycaemia. Indeed, both neural and microvascular abnormalities occurred only in the presence of moderate to poor control as judged by glycosylated haemoglobin. However, not all patients with the highest levels of glycaemia exhibited early complications, whereas in those with both neural and microvascular abnormalities the severity of each tended to be similar irrespective of the relative level of glycaemia.

These observations suggest two things. Firstly, although a certain level of hyperglycaemia is essential to initiate the development of complications, the inherent or acquired susceptibility of patients must vary resulting in differing severities of tissue damage for similar levels of glycaemic exposure. Secondly, the association of neural and microvascular complications, independent of glycaemia, also implies that there is either parallel development of abnormalities in different tissues, or an interdependent pathogenesis. However, from our data it is not possible to deduce which abnormalities; thus associations between developing complications could be due to such mechanisms as severe microangiopathy causing neuropathy [35], autonomically induced abnormalities of vascular autoregulation causing microangiopathy [36] or common activation of the sorbitol pathway [37] causing neural and microvascular damage in parallel.

We conclude that the early development of diabetic complications in young patients with Type 1 (insulin- 
dependent) diabetes is partly, but not simply, a function of poor glycaemic control; other factors, either intrinsic or environmental, must also be important.

Acknowledgments. This work was supported by grants from the British Diabetic Association and the Scottish Home and Health Department. Dr. D.J.Ewing is a Wellcome Trust Senior Lecturer.

\section{References}

1. Pirart J (1978) Diabetes mellitus and its degenerative complications: a prospective study of 4400 patients observed between 1947 and 1973. Diabetes Care 1: 168-88

2. Clarke BF, Ewing DJ, Campbell IW (1979) Diabetic autonomic neuropathy. Diabetologia 17: 195-212

3. Editorial (1983) Diabetic neuropathy - where are we now? Lancet 1: $1366-7$

4. Ewing DJ, Campbell IW, Clarke BF (1980) The natural history of diabetic autonomic neuropathy. Quart J Med 49: 95-108

5. Winegrad AI, Simmons DA, Martin DB (1983) Has one diabetic complication been explained? N Engl J Med 308: 152-4

6. Brown MJ, Asbury AK (1984) Diabetic neuropathy. Annals Neurology $15: 2-12$

7. Clements RS Jr, Bell D (1982) Diagnostic, pathogenetic and therapeutic aspects of diabetic neuropathy. Spec Top Endocrinol Metab 3: 1-43

8. Young RJ, Ewing DJ, Clarke BF (1983) Nerve function and metabolic control in teenage diabetics. Diabetes 32:142-7

9. Young RJ, Ewing DJ, Clarke BF (1983) A controlled trial of sorbinil, an aldose reductase inhibitor, in chronic painful neuropathy. Diabetes 32: 938-42

10. Tibi L, Young RJ, Smith AF (1982) Clinical implications of labile $\mathrm{HbA}_{1}$ as assayed by the electrophoretic method. Clin Chim Acta 126: $257-63$

11. Ewing DJ, Clarke BF (1982) Diagnosis and management of diabetic autonomic neuropathy. Br Med J 285:916-8

12. Viberti G, Keen H (1984) The pattern of proteinuria in diabetes mellitus. Relevance to pathogenesis and prevention of diabetic nephropathy. Diabetes 33: 686 92

13. Holman RR, Dornan TL, Mayon-White V, Howard-Williams $\mathbf{J}$, Orde-Pecker C, Jenkins L, et al (1983) Prevention of deterioration of renal and sensory-nerve function by more intensive management of insulin-dependent diabetic patients. Lancet 1: 204-8

14. Hillson RM, Hockaday TDR, Newton DJ (1984) Hyperglycaemia is one correlate of deterioration in vibration sense during the 5 years after diagnosis of Type 2 (non-insulin-dependent) diabetes. Diabetologia 26: 122-6

15. Gregersen $\mathrm{G}$ (1968) Variations in motor nerve conduction velocity produced by changes of the metabolic state in diabetic patients. Diabetologia 4: 273-7

16. Ward JD, Barnes CG, Fisher DJ, Jessop JD, Baker RWP (1971) Improvement in nerve function following treatment in newly diagnosed diabetes. Lancet 1: 428-31

17. Fraser DM, Campbell IW, Ewing DJ, Murray A, Neilson JMM, Clarke BF (1977) Peripheral and autonomic nerve function in newly diagnosed diabetes mellitus. Diabetes 26:546-50

18. Peterson CM, Jones RL, Dupuis A, Levine BS, Bernstein R, O'Shea M (1979) Feasibility of improved blood glucose control in patients with insulin dependent diabetes mellitus. Diabetes Care 2: $329-35$

19. Pietri A, Ehle AL, Raskin P (1980) Changes in nerve conduction velocity after six weeks of glucoregulation with portable insulin infusion pumps. Diabetes 29:668-71

20. Boulton AJM, Drury J, Clarke B, Ward JD (1982) Continuous subcutaneous insulin infusion in the management of painful diabetic neuropathy. Diabetes Care 5: 386-91
21. Graf RJ, Halter JB, Halar E, Porte D Jr (1979) Nerve conduction abnormalities in untreated maturity onset diabetes: relation to levels of fasting plasma and glycosylated hemoglobin. Ann Intern Med 90: 198-303

22. Graf RJ, Halter JB, Pfeifer MA, Halar E, Brozovich F, Porte D Jr (1981) Glycaemic control and nerve conduction abnormalities in non-insulin dependent diabetic subjects. Ann Intern Med 94: 307-11

23. Young RJ, Zhou YQ, Rodriguez E, Prescott RJ, Ewing DJ, Clarke BF (1986) Variable relationship between peripheral somatic and autonomic neuropathy in patients with different syndromes of diabetic polyneuropathy. Diabetes (in press)

24. Palmberg P, Smith M, Waltman S, Krupin T, Singer P, Burgess D, Wendlant T, Achtenberg J, Cryer P, Santiago J, White N, Kilo C, Daughaday W (1981) The natural history of retinopathy in insulin dependent juvenile-onset diabetes. Ophthalmology 88:613-8

25. Siperstein MD (1983) Diabetic microangiopathy and the control of blood glucose. N Engl J Med 309: 1577-9

26. Knowler WC, Bennet PH, Ballantine GJ (1980) Increased incidence of retinopathy in diabetics with elevated blood pressure. $\mathrm{N}$ Engl J Med 302: 645-50

27. Young RJ, McCulloch DK, Prescott RJ, Clarke BF (1984) Alcohol - another risk factor for diabetic retinopathy? $\mathrm{Br}$ Med $\mathrm{J} 288$ : 1035-7

28. Lauritzen T, Frost-Larsen K, Larsen HW, Deckert T, Steno Study Group (1983) Effect of 1 year of near normal blood glucose levels on retinopathy in insulin dependent diabetics. Lancet $1: 200-4$

29. Kroc collaborative study group (1984) Blood glucose control and the evolution of diabetic retinopathy and albuminuria: a preliminary multicentre trial. N Engl J Med 311:35-72

30. Dahl-Jorgensen K, Brinchmann-Hansen O, Hanssen KF, Sandvik L, Aagenaes O (1985) Rapid tightening of blood glucose control leads to transient deterioration of retinopathy in insulin dependent diabetes mellitus: the Oslo study. Br Med J 290: 811-5

31. Viberti GC, Hill RD, Jarrett RJ, Argypopoulos A, Mammud U, Keen H (1982) Microalbuminuria as a predictor of clinical nephropathy in insulin-dependent diabetes mellitus. Lancet 1: 1430-32

32. Mogensen CE, Christensen CK (1984) Predicting diabetic nephropathy in insulin dependent patients. $\mathrm{N}$ Engl $\mathbf{J}$ Med 311: 89-93

33. Mathieson ER, Oxenbull B, Johansen K, Svendsen PA, Deckert T (1984) Incipient nephropathy in type 1 (insulin-dependent) diabetes. Diabetologia 26: 406-10

34. Wiseman M, Viberti G, Mackintosh D, Jarrett RJ, Keen H (1984) Glycaemic, arterial pressure and microalbuminuria in Type 1 (insulin-dependent) diabetes mellitus. Diabetologia 26: 401-5

35. Williams E, Timperley WR, Ward JD, Duckworth T (1980) Electron microscopical studies of vessels in diabetic periheral neuropathy. J Clin Pathol 33: 462-70

36. Parving HH, Viberti GC, Christiansen JS, Lassen NA (1983) Haemodynamic factors in the genesis of diabetic microangiopathy. Metabolism 32: 943-9

37. Clarke BF, Young RJ, Martyn CN, Ewing DJ (1984) Aldose reductase inhibitors in diabetes: Sorbinil. Diabetic Medicine 1: $88-90$

Received: 13. August 1985

and in revised form: 11 December 1985

Dr. R.J. Young

Diabetic and Dietetic Department

Royal Infirmary

Edinburgh EH3 9YW

Scotland, UK 